\title{
Public Veterinary Medicine: Public Health
}

\section{Compendium of Animal Rabies Prevention and Control, 2016}

\author{
National Association \\ of State Public Health Veterinarians \\ Compendium of Animal Rabies Prevention \\ and Control Committee \\ Catherine M. Brown DVM, MSc, MPH (Co-Chair) \\ Sally Slavinski DVM, MPH (Co-Chair) \\ Paul Ettestad DVM, MS \\ Tom J. Sidwa DVM, MPH \\ Faye E. Sorhage VMD, MPH
}

\begin{abstract}
From the Massachusetts Department of Public Health, 305 South St, Jamaica Plain, MA 02130 (Brown); the New York City Department of Health and Mental Hygiene, 2 Gotham Center, CN\# 22A, 42-09 28th St, Queens, NY II I0I (Slavinski); the New Mexico Department of Health, I 190 St Francis Dr, Room N-I350, Santa Fe, NM 87502 (Ettestad); and the Texas Department of State Health Services, PO Box I49347, MC 1956, Austin, TX 787/4 (Sidwa).

Consultants to the Committee: Jesse Blanton, PhD (CDC, I600 Clifton Rd, Mailstop G-33, Atlanta, GA 30333); Richard B. Chipman, MS, MBA (USDA APHIS Wildlife Services, 59 Chenell Dr, Ste 2, Concord, NH 0330I); Rolan D. Davis, MS (Kansas State University, Room 1016 Research Park, Manhattan, KS 66506); Cathleen A. Hanlon,VMD, $\mathrm{PhD}$ (Retired); Jamie McAloon Lampman (McKamey Animal Center, $4500 \mathrm{~N}$ Access Rd, Chattanooga, TN 37415 [representing the National Animal Care and Control Association]); Joanne L. Maki, DVM, PhD (Merial a Sanofi Co, II 5 Trans Tech Dr, Athens, GA 3060I [representing the Animal Health Institute]); Michael C. Moore, DVM, MPH (Kansas State University, Room 1016 Research Park, Manhattan, KS 66506); Jim Powell, MS (Wisconsin State Laboratory of Hygiene, 465 Henry Mall, Madison, WI 53706 [representing the Association of Public Health Laboratories]); Charles E. Rupprecht, VMD, PhD (Wistar Institute of Anatomy and Biology, 360I Spruce St, Philadelphia, PA 19104); Geetha B. Srinivas, DVM, PhD (USDA Center for Veterinary Biologics, 1920 Dayton Ave, Ames, IA 500 I0); Nick Striegel, DVM, MPH (Colorado Department of Agriculture, 305 Interlocken Pkwy, Broomfield, CO 8002I); and Burton W. Wilcke Jr, PhD (University of Vermont, 302 Rowell Building, Burlington, VT 05405 [representing the American Public Health Association]).

Endorsed by the AVMA, American Public Health Association, Association of Public Health Laboratories, Council of State and Territorial Epidemiologists, and National Animal Care and Control Association.

This article has not undergone peer review.

Address correspondence to Dr. Brown (catherine.brown@state.ma.us).
\end{abstract}

$\mathbf{R}$ abies is a fatal viral zoonosis and serious public health problem. ${ }^{1}$ All mammals are believed to be susceptible to the disease, and for the purposes of this document, use of the term animal refers to mammals. The disease is an acute, progressive encephalitis caused by viruses in the genus Lyssavirus. ${ }^{2}$ Rabies virus is the most important lyssavirus globally. In the United States, multiple rabies virus variants are maintained in wild mammalian reservoir populations such as raccoons, skunks, foxes, and bats. Although the United States has been declared free from transmission of canine rabies virus variants, there is always a risk of reintroduction of these variants. ${ }^{3-7}$

The rabies virus is usually transmitted from animal to animal through bites. The incubation period is highly variable. In domestic animals, it is generally 3 to 12 weeks, but can range from several days to months, rarely exceeding 6 months. ${ }^{8}$ Rabies is communicable during the period of salivary shedding of rabies virus. Experimental and historic evidence documents that dogs, cats, and ferrets shed the virus for a few days prior to the onset of clinical signs and during illness. Clinical signs of rabies are variable and include inap- petance, dysphagia, cranial nerve deficits, abnormal behavior, ataxia, paralysis, altered vocalization, and seizures. Progression to death is rapid. There are currently no known effective rabies antiviral drugs.

The recommendations in this compendium serve as a basis for animal rabies prevention and control programs throughout the United States and facilitate standardization of procedures among jurisdictions, thereby contributing to an effective national rabies control program. The compendium is reviewed and revised as necessary, with the most current version replacing all previous versions. These recommendations do not supersede state and local laws or requirements. Principles of rabies prevention and control are detailed in Part I, and recommendations for parenteral vaccination procedures are presented in Part II. All animal rabies vaccines licensed by the USDA and marketed in the United States are listed and described in Appendix 1 , and contact information for manufacturers of these vaccines is provided in Appendix 2.

Modifications of note in this updated version of the compendium, compared with the previous version, ${ }^{9}$ include clarification of language, explicit en- 
couragement of an interdisciplinary approach to rabies control, a recommendation to collect and report at the national level additional data elements on rabid domestic animals, changes to the recommended management of dogs and cats exposed to rabies that are either unvaccinated or overdue for booster vaccination, reduction of the recommended 6-month quarantine period for certain species, and updates to the list of marketed animal rabies vaccines.

\section{Part I. Rabies Prevention and Control}

\section{A. Principles of rabies prevention and control}

1. Case definition. An animal is determined to be rabid after diagnosis by a qualified laboratory as specified (see Part I.A. 10. Rabies diagnosis). The national case definition for animal rabies requires laboratory confirmation on the basis of either a positive result for the direct fluorescent antibody test (preferably performed on CNS tissue) or isolation of rabies virus in cell culture or a laboratory animal. ${ }^{10}$

2. Rabies virus exposure. Rabies is transmitted when the virus is introduced into bite wounds, into open cuts in skin, or onto mucous membranes from saliva or other potentially infectious material such as neural tissue. ${ }^{11}$ Questions regarding possible exposures should be directed promptly to state or local public health authorities.

3. Interdisciplinary approach. Clear and consistent communication and coordination among relevant animal and human health partners across and within all jurisdictions (including international, national, state, and local) is necessary to most effectively prevent and control rabies. As is the case for the prevention of many zoonotic and emerging infections, rabies prevention requires the cooperation of animal control, law enforcement, and natural resource personnel; veterinarians; diagnosticians; public health professionals; physicians; animal and pet owners; and others. An integrated program must include provisions to promptly respond to situations; humanely restrain, capture, and euthanize animals; administer quarantine, confinement, and observation periods; and prepare samples for submission to a testing laboratory.

4. Awareness and education. Essential components of rabies prevention and control include ongoing public education, responsible pet ownership, routine veterinary care and vaccination, and professional continuing education. Most animal and human exposures to rabies can be prevented by raising awareness concerning rabies transmission routes, the importance of avoiding contact with wildlife, and the need for appropriate veterinary care. Prompt recognition and reporting of possible exposures to medical and veterinary professionals and local public health authorities are critical.

5. Human rabies prevention. Rabies in humans can be prevented by eliminating exposures to rabid animals or by providing exposed persons prompt postexposure prophylaxis consisting of local treatment of wounds in combination with appropriate administration of human rabies immune globulin and vaccine. An exposure assessment should occur before rabies postexposure prophylaxis is initiated and should include discussion between medical providers and public health officials. The rationale for recommending preexposure prophylaxis and details of both preexposure and postexposure prophylaxis administration can be found in the current recommendations of the Advisory Committee on Immunization Practices. ${ }^{11,12}$ These recommendations, along with information concerning the current local and regional epidemiology of animal rabies and the availability of human rabies biologics, are available from state health departments.

6. Domestic animal vaccination. Multiple vaccines are licensed for use in domestic animal species. Vaccines available include inactivated and modified-live virus vectored products, products for IM and SC administration, products with durations of immunity for periods of 1 to 3 years, and products with various minimum ages of vaccination. Recommended vaccination procedures are specified in Part II of this compendium; animal rabies vaccines licensed by the USDA and marketed in the United States are specified in Appendix 1. Local governments should initiate and maintain effective programs to ensure vaccination of all dogs, cats, and ferrets and to remove stray and unwanted animals. Such procedures have reduced laboratory-confirmed cases of rabies among dogs in the United States from 6,949 cases in 1947 to 89 cases in $2013 .{ }^{3}$ Because more rabies cases are reported annually involving cats (247 in 2013) than dogs, vaccination of cats should be required. ${ }^{3}$ Animal shelters and animal control authorities should establish policies to ensure that adopted animals are vaccinated against rabies.

An important tool to optimize public and animal health and enhance domestic animal rabies control is routine or emergency implementation of low-cost or free clinics for rabies vaccination. To facilitate implementation, jurisdictions should work with veterinary medical licensing boards, veterinary associations, the local veterinary community, animal control officials, and animal welfare organizations.

7. Rabies in vaccinated animals. Rabies is rare in vaccinated animals. ${ }^{13-15}$ If rabies is suspected in a vaccinated animal, it should be reported to public health officials, the vaccine manufacturer, and the USDA APHIS Center for Veterinary Biologics 
(www.aphis.usda.gov; search for "adverse event reporting"). The laboratory diagnosis should be confirmed and the virus variant characterized by the CDC's rabies reference laboratory.A thorough epidemiologic investigation including documentation of the animal's vaccination history and potential rabies exposures should be conducted.

8. Rabies in wildlife. It is difficult to control rabies among wildlife reservoir species. ${ }^{16}$ Vaccination of free-ranging wildlife or point infection control is useful in some situations, ${ }^{17}$ but the success of such procedures depends on the circumstances surrounding each rabies outbreak (See Part I. C. Prevention and control methods related to wildlife). Because of the risk of rabies in wild animals (especially raccoons, skunks, coyotes, foxes, and bats), the AVMA, American Public Health Association, Council of State and Territorial Epidemiologists, National Animal Care and Control Association, and National Association of State Public Health Veterinarians strongly recommend the enactment and enforcement of state laws prohibiting the importation, distribution, translocation, and private ownership of wild animals.

9. Rabies surveillance. Laboratory-based rabies surveillance and variant typing are essential components of rabies prevention and control programs. A comprehensive surveillance program should not be limited to testing only those animals that have potentially exposed people or domestic animals to rabies. Accurate and timely information and reporting are necessary to guide decisions regarding postexposure prophylaxis in potentially exposed humans, determine appropriate management of potentially exposed animals, aid in the discovery of emerging variants, describe the epidemiology of the disease, and assess the effectiveness of vaccination programs for domestic animals and wildlife. Every animal submitted for rabies testing should be reported to the CDC to evaluate surveillance trends. Public health authorities should implement electronic laboratory reporting and notification systems. ${ }^{18}$ Information reported on every animal submitted for rabies testing should include species, point location, vaccination status, rabies virus variant (if rabid), and human or domestic animal exposures. To enhance the ability to make evidencebased recommendations from national surveillance data, additional data should be collected and reported on all rabid domestic animals. In this regard, essential data elements include age, sex, neuter status, ownership status, quarantine dates (if any), date of onset of any clinical signs, and complete vaccination history. Rabid animals with a history of importation into the United States within the past 60 days are immediately notifiable by state health departments to the $\mathrm{CDC}$; for all indigenous cases, standard notification protocols should be followed. ${ }^{19}$

\section{Rabies diagnosis.}

a) The direct fluorescent antibody test is the gold standard for rabies diagnosis. The test should be performed in accordance with the established national standardized protocol (www.cdc.gov/rabies/pdf/rabiesdfaspv2. pdf) by a qualified laboratory that has been designated by the local or state health department. ${ }^{20,21}$ Animals submitted for rabies testing should be euthanized ${ }^{22,23}$ in such a way as to maintain the integrity of the brain so that the laboratory can recognize anatomic structures. Except in the case of very small animals, such as bats, only the head or entire brain (including brainstem) should be submitted to the laboratory. To facilitate prompt laboratory testing, submitted specimens should be stored and shipped under refrigeration without delay.The need to thaw frozen specimens will delay testing. Chemical fixation of tissues should be avoided to prevent significant testing delays and because such fixation might preclude reliable testing. Questions about testing of fixed tissues should be directed to the local rabies laboratory or public health department.

b) Rabies testing should be available outside of normal business hours at the discretion of public health officials to expedite exposure management decisions. ${ }^{20}$ When confirmatory testing is needed by state health departments (eg, in the event of inconclusive results, unusual species, or mass exposures), the CDC rabies laboratory can provide additional testing and results within 24 hours of sample receipt. ${ }^{24}$

c) Professional associations such as the Association of Public Health Laboratories should advocate for, distribute, and promote the development of guidelines for routinely assessing testing practices within rabies laboratories to ensure maintenance of quality and safety.

d) A direct rapid immunohistochemical test (referred to as dRIT) is being used by trained field personnel in surveillance programs for specimens not involved in human or domestic animal exposures. ${ }^{25-28}$ All positive direct rapid immunohistochemical test results need to be confirmed by means of direct fluorescent antibody testing at a qualified laboratory.

e) Currently, there are no commercially available, USDA-licensed rapid test kits for rabies diagnosis. Unlicensed tests should not be used owing to the following concerns: sensitivity and specificity of these tests are not known, the tests have not been validated against current standard methods, the excretion of virus in the saliva is intermittent and the amount varies over time, any unlicensed test result would 
need to be confirmed by validated methods such as direct fluorescent antibody testing on brain tissue, and the interpretation of results from unlicensed tests may place exposed animals and persons at risk.

11. Rabies serology. Some jurisdictions require evidence of vaccination and rabies virus antibodies for animal importation purposes. Rabies virus antibody titers are indicative of a response to vaccine or infection. Titers do not directly correlate with protection because other immunologic factors also play a role in preventing rabies and our abilities to measure and interpret those other factors are not well-developed. Therefore, evidence of circulating rabies virus antibodies in animals should not be used as a substitute for current vaccination in managing rabies exposures or determining the need for booster vaccination. ${ }^{29-32}$

12. Rabies research. Information derived from well-designed studies is essential for the development of evidence-based recommendations. Data are needed in several areas, including viral shedding periods for domestic livestock and lagomorphs, potential shedding of virus in milk, the earliest age at which rabies vaccination is effective, protective effect of maternal antibody, duration of immunity, postexposure prophylaxis protocols for domestic animals, models for treatment of clinical rabies, extralabel vaccine use in domestic animals and wildlife rabies reservoir species, host-pathogen adaptations and dynamics, and the ecology of wildlife rabies reservoir species, especially in relation to the use of oral rabies vaccines.

\section{B. Prevention and control methods in domestic and confined animals}

1. Preexposure vaccination and management. Adherence to a regular rabies vaccination schedule is critical to protect animals against recognized and unrecognized rabies exposures. Parenteral animal rabies vaccines should be administered only by or under the direct supervision of a licensed veterinarian on premises. Rabies vaccines may be administered under the supervision of a licensed veterinarian to animals held in animal shelters before release. ${ }^{33,34}$ The veterinarian signing a rabies vaccination certificate must ensure that the person who administered the vaccine is identified on the certificate and has been appropriately trained in vaccine storage, handling, and administration and in the management of adverse events. This ensures that a qualified and responsible person can be held accountable for properly vaccinating the animal.

Within 28 days after initial vaccination, a peak rabies virus antibody titer is expected, and the animal can be considered immunized. $31,35-37$ Regardless of the age of the animal at initial vaccination, a booster vaccination should be administered 1 year later (see Part II and Appendix 1). An animal is currently vaccinated and is consid- ered immunized immediately after any booster vaccination. ${ }^{38,39}$

a) Booster vaccination. Following the initial vaccination, booster vaccinations should be given in a manner consistent with the manufacturer's label. If a previously vaccinated animal is overdue for any booster vaccination, including the first booster vaccination due 1 year after initial vaccination, it should be given a booster vaccination. Immediately after this booster vaccination, the animal is considered currently vaccinated and should be placed on a booster vaccination schedule consistent with the label of the vaccine used. There are no laboratory or epidemiological data to support the annual or biennial administration of 3-year vaccines after completion of the initial vaccine series (ie, the initial vaccination and 1-year booster vaccination).

b) Dogs, cats, and ferrets.All dogs, cats, and ferrets should be vaccinated against rabies and revaccinated in accordance with recommendations in this compendium (Appendix 1).

c) Livestock. All horses should be vaccinated against rabies. ${ }^{40}$ Livestock, including species for which licensed vaccines are not available, that have frequent contact with humans (eg, in petting zoos, fairs, and other public exhibitions) should be vaccinated against rabies. ${ }^{41,42}$ Consideration should also be given to vaccinating livestock that are particularly valuable.

d) Captive wild animals and wild animal hybrids (the offspring of wild animals crossbred to domestic animals).

(1) Wild animals and wild animal hybrids should not be kept as pets. ${ }^{43,44}$ No parenteral rabies vaccines are licensed for use in wild animals or wild animal hybrids. ${ }^{45}$

(2) Animals that are farmed (eg, for food, fur, or fiber) or maintained in exhibits or zoological parks and that are not completely excluded from all contact with rabies vectors can become infected. ${ }^{46}$ Moreover, wild animals might be incubating rabies when initially captured. Therefore, wild-caught animals susceptible to rabies should be quarantined for a minimum of 6 months.

(3) Employees who work with animals in exhibits or zoological parks should receive preexposure rabies vaccination. The use of preexposure or postexposure rabies vaccination for handlers who work with animals at such facilities might reduce the need for euthanasia of captive animals that expose handlers. Carnivores and bats should be housed in a manner 
that precludes direct contact with the public. ${ }^{41,42}$ Consideration may be given to vaccinating animals that are particularly valuable (see Part II. D. Vaccination of wildlife and wild animal hybrids).

2. Stray animals. Stray dogs, cats, and ferrets should be removed from the community, and mechanisms should be put in place to facilitate voluntary surrender of animals to prevent abandonment. Local health departments and animal control officials can enforce the removal of strays more effectively if owned animals are required to have identification and be confined or kept on leash. Strays should be impounded for at least 3 business days to determine whether human exposure has occurred and to give owners sufficient time to reclaim animals.

Stray and feral cats serve as a significant source of rabies exposure risk. ${ }^{47}$ If communities allow maintenance of feral cat colonies despite this risk, they should safeguard the health of the cats and the communities in which they reside by requiring that cats receive initial rabies vaccinations and appropriately scheduled booster vaccinations.

\section{Importation and interstate movement of animals}

a) Areas with dog-to-dog rabies transmission. Canine rabies virus variants have been eliminated from the United States ${ }^{3,7}$; however, rabid dogs and a rabid cat have been introduced into the continental United States from areas with dog-to-dog rabies transmission. ${ }^{4-6,48,49}$ The movement of dogs for the purposes of adoption or sale from areas with dog-to-dog rabies transmission increases the risk of introducing canine-transmitted rabies to areas where it does not currently exist, and this practice should be prohibited.

b) International importation. Current federal regulations are insufficient to prevent the introduction of rabid animals into the United States and must be strengthened and appropriately enforced. ${ }^{4-6,48,49}$ The CDC and USDA APHIS have regulatory authority over the importation of dogs and cats into the United States. ${ }^{6}$ Importers of dogs must comply with rabies vaccination requirements. ${ }^{50,51}$ These regulations require that dogs from rabiesendemic countries be currently vaccinated against rabies prior to importation. The appropriate health official of the state of destination should be notified by the appropriate federal authorities within 72 hours of the arrival of any unvaccinated imported dog required to be placed in confinement (as defined by the $\mathrm{CDC}^{52}$ ) under these regulations. Failure of the owner to comply with these confinement requirements should be promptly reported to the CDC's Division of Global Migration and Quarantine (CDCAnimalImports@cdc.gov).

All imported dogs and cats are also subject to state and local laws governing rabies and should be currently vaccinated against rabies with USDA-licensed products in accordance with this compendium. Failure of the owner to comply with state or local requirements should be referred to the appropriate state or local official.

c) Interstate movement (including commonwealths and territories). Before interstate movement occurs, dogs, cats, ferrets, and horses should be currently vaccinated against rabies in accordance with this compendium.Animals in transit should be accompanied by a current, valid rabies vaccination certificate such as Form 51 from the National Association of State Public Health Veterinarians. ${ }^{53}$ When an interstate health certificate or certificate of veterinary inspection is required, it should contain the same rabies vaccination information as Form 51.

4. Adjunct procedures. Methods or procedures that enhance rabies control include the following ${ }^{54}$ :

a) Identification. Dogs, cats, and ferrets should be identified (eg, metal or plastic tags or microchips) to allow for verification of rabies vaccination status.

b) Licensure. Registration or licensure of all dogs, cats, and ferrets is an integral component of an effective rabies control program.A fee is frequently charged for such licensure, and revenues collected are used to maintain rabies or animal control activities. Evidence of current vaccination should be an essential prerequisite to licensure.

c) Canvassing. House-to-house canvassing by animal control officials facilitates enforcement of vaccination and licensure requirements.

d) Citations. Citations are legal summonses issued to owners for violations, including the failure to vaccinate or license their animals. The authority for officers to issue citations should be an integral part of animal control programs.

e) Animal control. All local jurisdictions should incorporate training and continuing education of personnel regarding stray-animal control, leash laws, animal bite prevention, and rabies prevention and control into their programs.

f) Public education. All local jurisdictions should incorporate education covering responsible pet ownership, bite prevention, and appropriate veterinary care into their programs.

5. Postexposure management. This section refers to any animal exposed (see Part I.A. 2. Rabies virus exposure) to a confirmed or suspected rabid animal. Wild mammalian carnivores, skunks, and bats that are not available or suitable for testing should be regarded as rabid. The rationale for 
observation, confinement, or strict quarantine periods of exposed animals despite previous vaccination is based in part on the potential for overwhelming viral challenge, incomplete vaccine efficacy, improper vaccine administration, variable host immunocompetence, and immune-mediated death (ie, early death phenomenon). ${ }^{13,55-57}$

a) Dogs, cats, and ferrets. Any illness in an exposed animal should be reported immediately to the local health department. If signs suggestive of rabies develop (eg, paralysis or seizures), the animal should be euthanized, and the head or entire brain (including brainstem) should be submitted for testing (see Part I.A. 10. Rabies diagnosis).

(1) Dogs, cats, and ferrets that are current on rabies vaccination should immediately receive veterinary medical care for assessment, wound cleansing, and booster vaccination. The animal should be kept under the owner's control and observed for 45 days.

(2) Dogs, cats, and ferrets that have never been vaccinated should be euthanized immediately. There are currently no USDA-licensed biologics for postexposure prophylaxis of previously unvaccinated domestic animals, and there is evidence that the use of vaccine alone will not reliably prevent the disease in these animals. ${ }^{58}$ If the owner is unwilling to have the animal euthanized, the animal should be placed in strict quarantine for 4 (dogs and cats) or 6 (ferrets) months. Strict quarantine in this context refers to confinement in an enclosure that precludes direct contact with people and other animals. A rabies vaccine should be administered at the time of entry into quarantine to bring the animal up to current rabies vaccination status.Administration of vaccine should be done as soon as possible. It is recommended that the period from exposure to vaccination not exceed 96 hours. ${ }^{59,60}$ If vaccination is delayed, public health officials may consider increasing the quarantine period for dogs and cats from 4 to 6 months, taking into consideration factors such as the severity of exposure, the length of delay in vaccination, current health status, and local rabies epidemiology.

(3) Dogs and cats that are overdue for a booster vaccination and that have appropriate documentation of having received a USDA-licensed rabies vaccine at least once previously should immediately receive veterinary medical care for assessment, wound cleansing, and booster vaccination. The animal should be kept under the own- er's control and observed for 45 days. ${ }^{39}$ If booster vaccination is delayed, public health officials may consider increasing the observation period for the animal, taking into consideration factors such as the severity of exposure, the length of delay in booster vaccination, current health status, and local rabies epidemiology.

(4) Dogs and cats that are overdue for a booster vaccination and without appropriate documentation of having received a USDA-licensed rabies vaccine at least once previously should immediately receive veterinary medical care for assessment, wound cleansing, and consultation with local public health authorities.

(a) The animal can be treated as unvaccinated, immediately given a booster vaccination, and placed in strict quarantine (see Part I. B. 5.a) (2)).

(b) Alternatively, prior to booster vaccination, the attending veterinarian may request guidance from the local public health authorities in the possible use of prospective serologic monitoring. Such monitoring would entail collecting paired blood samples to document prior vaccination by providing evidence of an anamnestic response to booster vaccination. If an adequate anamnestic response is documented, the animal can be considered to be overdue for booster vaccination (see Part I. B. 5. a) (3)) and observed for 45 days. ${ }^{39}$ If there is inadequate evidence of an anamnestic response, the animal is considered to have never been vaccinated and should be placed in strict quarantine (see Part I. B. 5.a) (2)).

(5) Ferrets that are overdue for a booster vaccination should be evaluated on a case-by-case basis, taking into consideration factors such as the severity of exposure, time elapsed since last vaccination, number of previous vaccinations, current health status, and local rabies epidemiology, to determine need for euthanasia or immediate booster vaccination followed by observation or strict quarantine.

b) Livestock. All species of livestock are susceptible to rabies; cattle and horses are the most frequently reported infected species. ${ }^{3}$ Any illness in an exposed animal should be reported immediately to the local health department and animal health officials. If signs suggestive of rabies develop, the animal should be euthanized, and the head or entire brain 
(including brainstem) should be submitted for testing (see Part I.A. 10. Rabies diagnosis).

(1) Livestock that have never been vaccinated should be euthanized immediately. Animals that are not euthanized should be confined and observed on a case-by-case basis for 6 months.

(2) Livestock that are current on rabies vaccination with a USDA-licensed vaccine approved for that species should be given a booster vaccination immediately and observed for 45 days.

(3) Livestock overdue for a booster vaccination should be evaluated on a case-by-case basis, taking into consideration factors such as severity of exposure, time elapsed since last vaccination, number of previous vaccinations, current health status, and local rabies epidemiology, to determine need for euthanasia or immediate booster vaccination followed by observation or strict quarantine.

(4) Multiple rabid animals in a herd and herbivore-to-herbivore transmission of rabies are uncommon. ${ }^{61}$ Therefore, restricting the rest of the herd if a single animal has been exposed to or infected with rabies is usually not necessary.

(5) Rabies virus is widely distributed in the tissues of rabid animals. ${ }^{62-64}$ Tissues and products from a rabid animal should not be used for human or animal consumption ${ }^{65,66}$ or transplantation. ${ }^{67}$ However, pasteurization and cooking will inactivate rabies virus. ${ }^{68}$ Therefore, inadvertently drinking pasteurized milk or eating thoroughly cooked animal products does not constitute a rabies exposure.

(6) Handling and consumption of uncooked tissues from exposed animals might carry a risk for rabies transmission. ${ }^{69}$ Persons handling exposed animals, carcasses, and tissues should use appropriate barrier precautions. ${ }^{69,70}$ State and local public health authorities, state meat inspectors, and the USDA Food Safety and Inspection Service should be notified if exposures occur in animals intended for commercial use. Animals should not be presented for slaughter in a USDA-regulated establishment if such animals originate from a quarantine area and have not been approved for release by the proper authority. If an exposed animal is to be custom slaughtered or home slaughtered for consumption, it should be slaughtered immediately after exposure, and all tissues should be cooked thoroughly.

c) Other animals. Other mammals exposed to a rabid animal should be euthanized immediately. Animals maintained in USDAlicensed research facilities or accredited zoological parks should be evaluated on a case-bycase basis in consultation with public health authorities. Management options may include quarantine, observation, or administration of rabies biologics.

\section{Management of animals that bite humans.}

a) Dogs, cats, and ferrets. Rabies virus is excreted in the saliva of infected dogs, cats, and ferrets during illness and for only a few days before the onset of clinical signs or death. ${ }^{71-73}$ Regardless of rabies vaccination status, a healthy dog, cat, or ferret that exposes a person should be confined and observed daily for 10 days from the time of the exposure $^{74}$; administration of rabies vaccine to the animal is not recommended during the observation period to avoid confusing signs of rabies with rare adverse vaccine reactions. ${ }^{15}$ Any illness in the animal should be reported immediately to the local health department. Such animals should be evaluated by a veterinarian at the first sign of illness during confinement. If signs suggestive of rabies develop, the animal should be euthanized, and the head or entire brain (including brainstem) should be submitted for testing (see Part I. A. 10. Rabies diagnosis). Any stray or unwanted dog, cat, or ferret that exposes a person may be euthanized immediately, and the head or entire brain (including brainstem) should be submitted for testing (see Part I.A. 10. Rabies diagnosis).

b) Other animals. Other animals that might have exposed a person to rabies should be reported immediately to the local health department. Management of animals other than dogs, cats, and ferrets depends on the species, the circumstances of the exposure, the epidemiology of rabies in the area, the exposing animal's history and current health status, and the animal's potential for exposure to rabies. The shedding period for rabies virus is undetermined for most species. Previous vaccination of these animals might not preclude the necessity for euthanasia and testing.

7. Outbreak prevention and control. The emergence of new rabies virus variants or the introduction of nonindigenous viruses poses a significant risk to humans, domestic animals, and wildlife. ${ }^{75-82}$ $A$ rapid and comprehensive response involves coordination of multiple agencies (see Part I. A. 3. Interdisciplinary approach) to accomplish the following outcomes ${ }^{83}$ :

- Characterize the virus at the national reference laboratory.

- Identify and control the source of the introduction. 
- Enhance laboratory-based surveillance in wild and domestic animals.

- Increase animal rabies vaccination rates.

- Restrict the movement of animals.

- Evaluate the need for wildlife intervention activities (eg, point infection control, trapvaccinate-release programs, and oral rabies vaccination programs).

- $\quad$ Provide public and professional outreach and education.

8. Disaster response. Animals might be displaced during and after man-made or natural disasters and require emergency sheltering. ${ }^{84-86}$ Animal rabies vaccination and exposure histories are often not available for displaced animals, and disaster response can create situations where animal caretakers might lack appropriate training or preexposure vaccination. In such situations, it is critical to implement and coordinate rabies prevention and control measures to reduce the risk of rabies transmission and the need for human postexposure prophylaxis. Such measures include the following actions:

- Coordinate relief efforts of individuals and organizations with the local emergency operations center before deployment.

- Examine each animal at a triage site for possible bite injuries or signs of rabies.

- Isolate animals exhibiting signs of rabies pending evaluation by a veterinarian.

- Ensure that all animals have a unique identifier.

- Administer a rabies vaccine to all dogs, cats, and ferrets unless reliable proof of current vaccination exists.

- Adopt minimum standards for animal caretakers as feasible, including use of personal protective equipment, completion of the preexposure rabies vaccination series prior to deployment, and provision of appropriate training. ${ }^{87}$

- Maintain documentation of animal disposition and location (eg, returned to owner, died or euthanized, adopted, or relocated to another shelter with address of new location).

- Provide facilities to confine and observe animals involved in exposures (see Part I. B. 6. Management of animals that bite humans).

- Report human exposures to appropriate public health authorities (see Part I. A. 2. Rabies virus exposure).

\section{Prevention and control methods related to wildlife}

The public should be warned not to handle or feed wild mammals. Wild mammals and wild animal hybrids that expose persons, pets, or livestock should be considered for euthanasia and rabies testing. A person exposed by any wild mammal should immediately wash the wound thoroughly and report the incident to a health-care provider who, in consultation with public health authorities, can evaluate the need for postexposure prophylaxis. ${ }^{11,12}$
Translocating infected wildlife has contributed to the spread of rabies, ${ }^{75-80,88}$ and animals that appear healthy can still be rabid. Therefore, translocation (ie, moving live animals from their point of capture and releasing them) of known rabies reservoir species should be prohibited. ${ }^{89}$ Whereas state-regulated wildlife rehabilitators and nuisance-wildlife control operators should play a role in a comprehensive rabies control program, minimum standards for these persons who handle wild mammals should include rabies preexposure vaccination, specific rabies prevention and control training, and ongoing continuing education.

1. Carnivores. The use of oral rabies vaccines for mass vaccination of free-ranging wildlife should be considered in selected situations, with the approval of appropriate state and local agencies. ${ }^{16,90}$ There have been documented successes using oral rabies vaccines to control rabies in wildlife in North America. ${ }^{90-93}$ The currently licensed vaccinia-vectored oral rabies vaccine is labeled for use in raccoons and coyotes. Research to improve existing oral rabies vaccine and baits and to develop and test novel products to determine safety and efficacy must be encouraged. The distribution of oral rabies vaccines should be based on scientific assessments of the target species and followed by timely and appropriate analysis of surveillance data, with results provided to all stakeholders. In addition, parenteral vaccination (trap-vaccinate-release) of wildlife rabies reservoir species may be integrated into coordinated oral rabies vaccine programs to enhance their effectiveness. Continuous and persistent programs for trapping or poisoning wildlife are not effective in reducing populations of wildlife rabies reservoir species on a statewide basis. However, limited population control in high-contact areas (eg, picnic grounds, camps, and suburban areas) might be indicated for the removal of selected highrisk species of wildlife. State agriculture, public health, and wildlife agencies should be consulted for planning, coordination, and evaluation of vaccination or point infection control programs. ${ }^{16}$

2. Bats. From the 1950 s to today, indigenous rabid bats have been reported from every state except Hawaii and have caused rabies in at least 54 humans in the United States. ${ }^{94-103}$ Bats should be excluded, using appropriate methods, from houses, public buildings, and adjacent structures to prevent direct association with humans. ${ }^{104,105}$ Such structures should then be made bat-proof by sealing entrances used by bats. Controlling rabies in bats through programs designed to reduce bat populations is neither feasible nor desirable.

\section{Part II. Recommendations for Parenteral Rabies Vaccination Procedures}

\section{A. Vaccine administration}

All animal rabies vaccines should be restricted to use by or under the direct supervision of a veterinar- 
ian, ${ }^{106}$ except as recommended otherwise (see Part I. B. 1. Preexposure vaccination and management).

\section{B. Vaccine selection}

All vaccines licensed by the USDA and marketed in the United States at the time of publication of this compendium are listed (Appendix 1). Newly approved vaccines and changes in label specifications made subsequent to publication should be considered as part of this list. Any of the listed vaccines can be used for revaccination, even if the product is not the same as the one previously administered. Vaccines used in state and local rabies control programs should have at least a 3-year duration of immunity. This constitutes the most effective method of increasing the proportion of immunized dogs and cats in any population. ${ }^{107}$

\section{C.Adverse events}

Currently, no epidemiological association exists between any particular licensed vaccine product and adverse events. ${ }^{15,34,108-110}$ Although rare, adverse events such as vomiting, injection site swelling, lethargy, hypersensitivity, and the occurrence of rabies despite previous vaccination of an animal have been reported. Adverse events should be reported to the vaccine manufacturer and to USDA APHIS's Center for Veterinary Biologics (www.aphis.usda.gov; search for "adverse event reporting"). Although ill animals may not have a full immunologic response to vaccination, there is no evidence to suggest that adverse events are more likely to occur with rabies vaccination of ill than healthy animals. A veterinarian choosing to temporarily delay vaccinating an animal with an acute illness or condition should ensure that the animal is vaccinated as soon as possible.Animals with a previous history of anaphylaxis can be medically managed and observed after vaccination. ${ }^{56}$ Severe adverse events related to rabies vaccination are extremely rare in animals. Decisions concerning rabies vaccination of animals with well-documented severe adverse events to rabies vaccine must be made within the context of a valid veterinarian-client-patient relationship. Due consideration should be given to the attendant risks and benefits of not vaccinating, including regulatory noncompliance. Animals not currently vaccinated that experience a rabies exposure are at greater risk for infection and death and also put their owners and the community at risk.

\section{Vaccination of wildlife and wild animal hybrids}

The safety and efficacy of parenteral rabies vaccines in wildlife and wild animal hybrids have not been established, and no rabies vaccines are currently licensed for use in these animals. Thus, any use of rabies vaccines in these animals is considered extralabel use. Zoos or research institutions may establish vaccination programs in an attempt to protect valuable animals, but these should not replace appropriate public health activities that protect humans (see Part I. B. 1.d) (3)).

\section{E. Accidental human exposure to rabies vaccines}

Human exposure to parenteral animal rabies vaccines listed in Appendix 1 does not constitute a risk for rabies virus infection. Human exposure to vacciniavectored oral rabies vaccines should be reported to state health officials. ${ }^{111,112}$

\section{F. Rabies certificates}

All agencies and veterinarians should use Form 51, the rabies vaccination certificate recommended by the National Association of State Public Health Veterinarians, ${ }^{53}$ or should use an equivalent. The form must be completed in full and signed by the administering or supervising veterinarian. Computer-generated forms containing the same information are also acceptable.

\section{References}

1. Rabies. In: Heymann D, ed. Control of communicable diseases manual. 20th ed. Washington, DC:American Public Health Association, 2015; 497-508.

2. International Committee on Taxonomy of Viruses. Virus taxonomy: 2014 release. Order Mononegavirales: family Rbabdoviridae: genus Lyssavirus. 2014.Available at: www.ictvonline. org/virusTaxonomy.asp.Accessed Jun 15, 2015.

3. Dyer JL, Yager P, Orciari L, et al. Rabies surveillance in the United States during 2013. J Am Vet Med Assoc 2014;245:11111123 .

4. Castrodale L, Walker V, Baldwin J, et al. Rabies in a puppy imported from India to the USA, March 2007. Zoonoses Public Health 2008;55:427-430

5. CDC. Rabies in a dog imported from Iraq-New Jersey, June 2008. MMWR Morb Mortal Wkly Rep 2008;57:1076-1078.

6. McQuiston JH,Wilson T, Harris S, et al. Importation of dogs into the United States: risks from rabies and other zoonotic diseases. Zoonoses Public Health 2008;55:421-426.

7. Velasco-Villa A, Reeder SA, Orciari LA, et al. Enzootic rabies elimination from dogs and reemergence in wild terrestrial carnivores, United States. Emerg Infect Dis 2008;14:18491854 .

8. Beran GW. Rabies and infections by rabies-related viruses. In: Beran GW, ed. Handbook of zoonoses section B: viral. 2nd ed. Boca Raton, Fla: CRC Press, 1994;307-357.

9. Brown CM, Conti L, Ettestad P, et al. Compendium of animal rabies prevention and control, 2011. J Am Vet Med Assoc 2011;239;609-617.

10. Council of State and Territorial Epidemiologists Infectious Disease Subcommittee. Public bealth reporting and national notification for animal rabies. 09-ID-12.Atlanta: Council of State and Territorial Epidemiologists, 2009. Available at: c.ymcdn. com/sites/www.cste.org/resource/resmgr/PS/09-ID-12.pdf. Accessed Jun 15, 2015.

11. Manning SE, Rupprecht CE, Fishbein D, et al. Human rabies prevention-United States, 2008. Recommendations of the Advisory Committee on Immunization Practices. MMWR Recomm Rep 2008;57(RR-3):1-28.

12. Rupprecht CE, Briggs D, Brown CM, et al. Use of a reduced (4-dose) vaccine schedule for postexposure prophylaxis to prevent human rabies. Recommendations of the Advisory Committee on Immunization Practices. MMWR Recomm Rep 2010;59(RR-2):1-9.

13. McQuiston JH, Yager PA, Smith JS, et al. Epidemiologic characteristics of rabies virus variants in dogs and cats in the United States, 1999. J Am Vet Med Assoc 2001;218:19391942.

14. Murray $\mathrm{KO}$, Holmes $\mathrm{KC}$, Hanlon CA. Rabies in vaccinated dogs and cats in the United States, 1997-2001.J Am Vet Med Assoc 2009;235:691-695. 
15. Frana TS, Clough NE, Gatewood DM, et al. Postmarketing surveillance of rabies vaccines for dogs to evaluate safety and efficacy. J Am Vet Med Assoc 2008;232:1000-1002.

16. Hanlon CA, Childs JE, Nettles VF, et al. Recommendations of a national working group on prevention and control of rabies in the United States.Article III: rabies in wildlife.J Am Vet Med Assoc 1999;215:1612-1618.

17. Slate $\mathrm{D}$, Algeo TD, Nelson KM, et al. Oral rabies vaccination in North America: opportunities, complexities, and challenges. PLoS Negl Trop Dis 2009;3:e549.

18. Council of State and Territorial Epidemiologists Surveillance/ Informatics Subcommittee. Recommendations for the implementation of electronic laboratory reporting in the United States. 09-SI-03. Atlanta: Council of State and Territorial Epidemiologists, 2009. Available at: c.ymcdn.com/sites/www.cste org/resource/resmgr/PS/09-SI-03.pdf.Accessed Jun 15, 2015.

19. Council of State and Territorial Epidemiologists Surveillance/ Informatics Subcommittee. Process statement for immediately nationally notifiable conditions. 09-SI-04. Available at: c.ymcdn.com/sites/www.cste.org/resource/resmgr/PS/09SI-04.pdf.Accessed Jun 15, 2015.

20. Hanlon CA, Smith JS, Anderson GR, et al. Recommendations of a national working group on prevention and control of rabies in the United States. Article II: laboratory diagnosis of rabies. J Am Vet Med Assoc 1999;215:1444-1446.

21. Rudd RJ, Smith JS,Yager PA, et al.A need for standardized rabiesvirus diagnostic procedures: effect of cover-glass mountant on the reliability of antigen detection by the fluorescent antibody test. Virus Res 2005;111:83-88.

22. AVMA. AVMA guidelines for the euthanasia of animals: 2013 edition. Available at www.avma.org/KB/Policies/Documents/ euthanasia.pdf.Accessed Jun 15, 2015

23. American Association of Zoo Veterinarians. Guidelines for the euthanasia of nondomestic animals. Yulee, Fla:American Association of Zoo Veterinarians, 2006.

24. CDC. Public health response to a potentially rabid bear cubIowa, 1999. MMWR Morb Mortal Wkly Rep 1999;48:971-973.

25. Niezgoda M, Rupprecht CE. Standard operating procedure for the direct rapid immunobistochemistry test (DRIT) for the detection of rabies virus antigen. Atlanta: $\mathrm{CDC}, 2006$. Available at: rabiessurveillanceblueprint.org/IMG/pdf/cdc_drit_sop.pdf. Accessed Jun 15, 2015.

26. Lembo T, Niezgoda M, Velasco-Villa A, et al. Evaluation of a direct, rapid immunohistochemical test for rabies diagnosis. Emerg Infect Dis 2006;12:310-313.

27. Dürr S, Naïssengar S, Mindekem R, et al. Rabies diagnosis for developing countries. PLoS Negl Trop Dis 2008;2:e206.

28. Saturday GA, King R, Fuhrmann L. Validation and operational application of a rapid method for rabies antigen detection. US Army Med Dep J 2009;Jan-Mar:42-45.

29. Tizard I, Ni Y. Use of serologic testing to assess immune status of companion animals. J Am Vet Med Assoc 1998;213:54-60.

30. Greene CE. Rabies and other lyssavirus infections. In: Greene $\mathrm{CE}$, ed. Infectious diseases of the dog and cat. $3 \mathrm{rd}$ ed. London: Saunders Elsevier, 2006;167-183.

31. Rupprecht CE, Gilbert J, Pitts R, et al. Evaluation of an inactivated rabies virus vaccine in domestic ferrets. $\mathrm{J} \mathrm{Am} \mathrm{Vet} \mathrm{Med}$ Assoc 1990;196:1614-1616.

32. Moore SM, Hanlon CA. Rabies-specific antibodies: measuring surrogates of protection against a fatal disease. PLoS Negl Trop Dis 2010; $4: \mathrm{e} 595$.

33. Welborn LV, DeVries JG, Ford R, et al. 2011 AAHA canine vaccination guidelines. J Am Anim Hosp Assoc 2011;47:1-42.

34. Scherk MA, Ford RB, Gaskell RM, et al. 2013 AAFP feline vaccination advisory panel report.J Feline Med Surg 2013;15:785808.

35. Aubert MF. Practical significance of rabies antibodies in cats and dogs. Rev Sci Tech 1992;11:735-760.

36. Muirhead TL, McClure JT, Wichtel JJ, et al. The effect of age on serum antibody titers after rabies and influenza vaccination in healthy horses.J Vet Intern Med 2008;22:654-661.

37. Shimazaki $\mathrm{Y}$, Inoue $\mathrm{S}$, Takahashi $\mathrm{C}$, et al. Immune response to Japanese rabies vaccine in domestic dogs.J Vet Med B Infect Dis Vet Public Health 2003;50:95-98.
38. Cliquet F,VerdierY, Sagné L, et al. Neutralising antibody titration in 25,000 sera of dogs and cats vaccinated against rabies in France, in the framework of the new regulations that offer an alternative to quarantine. Rev Sci Tech 2003;22:857-866.

39. Moore MC, Davis RD, Kang Q, et al. Comparison of anamnestic responses to rabies vaccination in dogs and cats with current and out-of-date vaccination status. J Am Vet Med Assoc 2015;246:205-211.

40. American Association of Equine Practitioners. Core vaccination guidelines: rabies. Available at: www.aaep.org/-i-165.html. Accessed Jun 15, 2015.

41. National Association of State Public Health Veterinarians Animal Contact Compendium Committee 2013. Compendium of Measures to Prevent Disease Associated with Animals in Public Settings, 2013.J Am Vet Med Assoc 2013;243:1270-1288.

42. Bender JB, Shulman SA, Animals in Public Contact Subcommittee of the National Association of State Public Health Veterinarians. Reports of zoonotic disease outbreaks associated with animal exhibits and availability of recommendations for preventing zoonotic disease transmission from animals to people in such settings. J Am Vet Med Assoc 2004;224:1105-1109.

43. AVMA. Position on canine hybrids. Available at: www.avma. org/KB/Policies/Pages/canine-hybrids.aspx. Accessed Jun 15, 2015.

44. Siino BS. Crossing the line: the case against hybrids. ASPCA Animal Watch 2000; Winter:22-29.

45. Jay MT, Reilly KF, DeBess EE, et al. Rabies in a vaccinated wolfdog hybrid. J Am Vet Med Assoc 1994;205:1729-1732.

46. Petersen BW, Tack DM, Longenberger A, et al. Rabies in captive deer, Pennsylvania, USA, 2007-2010. Emerg Infect Dis 2012;18:138-141.

47. Roebling AD, Johnson D, Blanton JD, et al. Rabies prevention and management of cats in the context of trap-neuter-vaccinerelease programmes. Zoonoses Public Health 2014;61:290-296.

48. CDC.An imported case of rabies in an immunized dog. MMWR Morb Mortal Wkly Rep 1987;36:94-96.

49. CDC. Imported dog and cat rabies-New Hampshire, California. MMWR Morb Mortal Wkly Rep 1988;37:559-560.

50. Rabies vaccination requirements for dogs. 42 CFR $\$ 71.51(\mathrm{c})$.

51. CDC. Bringing a dog into the United States. Available at: www. cdc.gov/animalimportation/dogs.html.Accessed Nov 25, 2015.

52. CDC. Frequently asked questions. Available at: www.cdc.gov/ animalimportation/lawsregulations/frequently-asked-questions. html\#Confinement.Accessed Nov 25, 2015.

53. National Association of State Public Health Veterinarians. Rabies vaccination certificate. Available at: www.nasphv.org/ Documents/RabiesVacCert.pdf.Accessed Nov 25, 2015.

54. Global Alliance for Rabies Control. Rabies blueprint. Available at: www.rabiesblueprint.com.Accessed Nov 25, 2015.

55. Rabies vaccine, killed virus. 9 CFR 113.209

56. Greene CE. Immunoprophylaxis. In: Greene CE, ed. Infectious diseases of the dog and cat. 3rd ed. London: Saunders Elsevier, 2006;1069-1119.

57. Willoughby RE. "Early death" and the contraindication of vaccine during rabies treatment. Vaccine 2009;27:7173-7177.

58. Hanlon CA, Niezgoda M, Rupprecht CE. Postexposure prophylaxis for prevention of rabies in dogs. Am J Vet Res 2002;63:1096-1100.

59. Wilson PJ, Clark KA. Postexposure rabies prophylaxis protocol for domestic animals and epidemiologic characteristics of rabies vaccination failures in Texas: 1995-1999. J Am Vet Med Assoc 2001;218:522-525

60. Wilson PJ, Oertli EH, Hunt PR, et al. Evaluation of a postexposure rabies prophylaxis protocol for domestic animals in Texas: 2000-2009. J Am Vet Med Assoc 2010;237:1395-1401.

61. Mansfield K, McElhinney L, Hübschle O, et al.A molecular epidemiological study of rabies epizootics in kudu (Tragelaphus strepsiceros) in Namibia. BMC Vet Res 2006;2:2-11.

62. Debbie JG,Trimarchi CV. Pantropism of rabies virus in free-ranging rabid red fox (Vulpes fulva). JWildl Dis 1970;6:500-506

63. Fekadu M, Shaddock JH. Peripheral distribution of virus in dogs inoculated with two strains of rabies virus. Am J Vet Res 1984; $45: 724-729$

64. Charlton KM. The pathogenesis of rabies and other lyssavi- 
ral infections: recent studies. Curr Top Microbiol Immunol 1994;187:95-119.

65. Afshar A.A review of non-bite transmission of rabies virus infection. Br Vet J 1979;135:142-148.

66. CDC. Mass treatment of humans who drank unpasteurized milk from rabid cows-Massachusetts, 1996-1998. MMWR Morb Mortal Wkly Rep 1999;48:228-229.

67. CDC. Public health service guideline on infectious disease is sues in xenotransplantation.MMWR Recomm Rep 2001;50(RR15): $1-46$

68. Turner GS, Kaplan C. Some properties of fixed rabies virus J Gen Virol 1967;1:537-551.

69. Wertheim HFL, Nguyen TQ, Nguyen KAT, et al. Furious rabies after an atypical exposure. PLoS Med 2009;6:e1000044.

70. US Department of Health and Human Services.Viral agents. In:Biosafety in microbiological and biomedical laboratories. 5th ed. Washington, DC: US Government Printing Office, 2007;234-235.

71. Vaughn JB, Gerhardt P, Paterson JC. Excretion of street rabies virus in saliva of cats. JAMA 1963;184:705-708

72. Vaughn JB, Gerhardt P, Newell KW. Excretion of street rabies virus in the saliva of dogs. JAMA 1965;193:363-368.

73. Niezgoda M, Briggs DJ, Shaddock J, et al.Viral excretion in domestic ferrets (Mustela putorius furo) inoculated with a raccoon rabies isolate. Am JVet Res 1998;59:1629-1632.

74. Tepsumethanon V, Lumlertdacha B, Mitmoonpitak C, et al. Survival of naturally infected rabid dogs and cats. Clin Infect Dis 2004;39:278-280.

75. Jenkins SR, Perry BD, Winkler WG. Ecology and epidemiology of raccoon rabies. Rev Infect Dis 1988;10(suppl 4):S620-S625.

76. CDC. Translocation of coyote rabies-Florida, 1994. MMWR Morb Mortal Wkly Rep 1995;44:580-581, 587.

77. Rupprecht CE, Smith JS, Fekadu M, et al.The ascension of wildlife rabies: a cause for public health concern or intervention? Emerg Infect Dis 1995;1:107-114.

78. Constantine DG. Geographic translocation of bats: known and potential problems. Emerg Infect Dis 2003;9:17-21.

79. Krebs JW, Strine TW, Smith JS, et al. Rabies surveillance in the United States during 1993 (Erratum published in J Am Vet Med Assoc 1995;206:650). JAm Vet Med Assoc 1994;205:1695-1709.

80. Nettles VF, Shaddock JH, Sikes RK, et al. Rabies in translocated raccoons. Am J Public Health 1979;69:601-602.

81. Engeman RM, Christensen KL, Pipas MJ, et al. Population monitoring in support of a rabies vaccination program for skunks in Arizona.J Wildl Dis 2003;39:746-750.

82. Leslie MJ, Messenger S, Rohde RE, et al. Bat-associated rabies virus in skunks. Emerg Infect Dis 2006;12:1274-1277.

83. Rupprecht CE, Hanlon CA, Slate D. Control and prevention of rabies in animals: paradigm shifts. Dev Biol (Basel) 2006;125:103-111.

84. Pets Evacuation and Transportations Standards Act of 2006 Public Law 109-308.

85. CDC. Disaster information for pet shelters. Available at: www. bt.cdc.gov/disasters/petshelters.asp.Accessed Nov 25, 2015

86. AVMA. Disaster preparedness for veterinarians. Available at www.avma.org/disaster/default.asp.Accessed Nov 25, 2015.

87. National Animal Control Association. Guidelines. Available at: c.ymcdn.com/sites/www.nacanet.org/resource/resmgr/Docs/ NACA_Guidelines.pdf.Accessed Jun 15, 2015

88. Chipman R, Slate D, Rupprecht C, et al. Downside risk of translocation. Dev Biol (Basel) 2008;131:223-232

89. The Wildlife Society. Standing position statement: wildlife disease. Available at: wildlife.org/wp-content/uploads/2015/04/ SP_WildlifeDisease1.pdf.Accessed Jun 15, 2015.
90. Slate D, Rupprecht CE, Rooney JA, et al. Status of oral rabies vaccination in wild carnivores in the United States. Virus Res 2005; 111:68-76.

91. Sidwa TJ, Wilson PJ, Moore GM, et al. Evaluation of oral rabies vaccination programs for control of rabies epizootics in coyotes and gray foxes: 1995-2003. J Am Vet Med Assoc 2005;227:785-792.

92. MacInnes CD, Smith SM, Tinline RR, et al. Elimination of rabies from red foxes in eastern Ontario. JWildl Dis 2001;37:119-132.

93. Rosatte RC, Power MJ, Donovan D, et al. Elimination of arctic variant of rabies in red foxes, metropolitan Toronto. Emerg Infect Dis 2007;13:25-27.

94. Messenger SL, Smith JS, Rupprecht CE. Emerging epidemiology of bat-associated cryptic cases of rabies in humans in the United States. Clin Infect Dis 2002;35:738-747.

95. De Serres G, Dallaire F, Cote M, et al. Bat rabies in the United States and Canada from 1950-2007: human cases with and without bat contact. Clin Infect Dis 2008;46:1329-1337.

96. CDC. Human rabies-Missouri, 2008. MMWR Morb Mortal Wkly Rep 2009:58:1207-1209.

97. CDC. Human rabies-Kentucky/Indiana, 2009. MMWR Morb Mortal Wkly Rep 2010;59:393-396.

98. CDC. Human rabies-Virginia, 2009. MMWR Morb Mortal Wkly Rep 2010;59:1236-1238.

99. CDC. Presumptive abortive human rabies-Texas, 2009. MMWR Morb Mortal Wkly Rep 2010;59:185-190.

100. CDC. Human rabies-Michigan, 2009. MMWR Morb Mortal Wkly Rep 2011;60:437-440.

101. CDC. Human rabies-Wisconsin, 2010. MMWR Morb Mortal Wkly Rep 2011;60:1164-1166.

102. CDC. US-acquired human rabies with symptom onset and diagnosis abroad, 2012.MMWR Morb Mortal Wkly Rep 2012;61:777-781.

103. CDC. Human rabies-South Carolina, 2011. MMWR Morb Mortal Wkly Rep 2013;62:642-644.

104. Greenhall AM. House bat management. Resource publication 143. Falls Church,Va: US Fish and Wildlife Service, 1982.

105. Greenhall AM, Frantz SC. Bats. In: Hygnstrom SE, Timm RM, Larson GE, eds. Prevention and control of wildlife damage-1994.Available at:icwdm.org/handbook/mammals/bats. asp.Accessed Jun 15, 2015.

106. AVMA. Model rabies control ordinance.Available at: www.avma org/KB/Policies/Documents/avma-model-rabies-ordinance.pdf. Accessed Jun 15, 2015.

107. Bunn TO. Canine and feline vaccines, past and present. In: Baer GM, ed. The natural bistory of rabies. 2nd ed. Boca Raton, Fla: CRC Press Inc, 1991;415-425.

108. Macy DW, Hendrick MJ. The potential role of inflammation in the development of postvaccinal sarcomas in cats. Vet Clin North Am Small Anim Pract 1996;26:103-109.

109. Gobar GM, Kass PH.World Wide Web-based survey of vaccination practices, postvaccinal reactions, and vaccine site-associated sarcomas in cats. J Am Vet Med Assoc 2002;220:14771482 .

110. Kass PH, Spangler WL, Hendrick MJ, et al. Multicenter casecontrol study of risk factors associated with development of vaccine-associated sarcomas in cats. J Am Vet Med Assoc 2003;223:1283-1292

111. Rupprecht CE, Blass L, Smith K, et al. Human infection due to recombinant vaccinia-rabies glycoprotein virus. $N$ Engl J Med 2001;345:582-586.

112. CDC. Human vaccinia infection after contact with a raccoon rabies vaccine bait- Pennsylvania, 2009. MMWR Morb Mortal Wkly Rep 2009;58:1204-1207. 


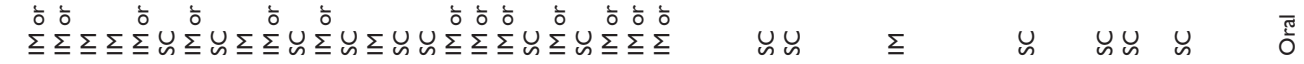

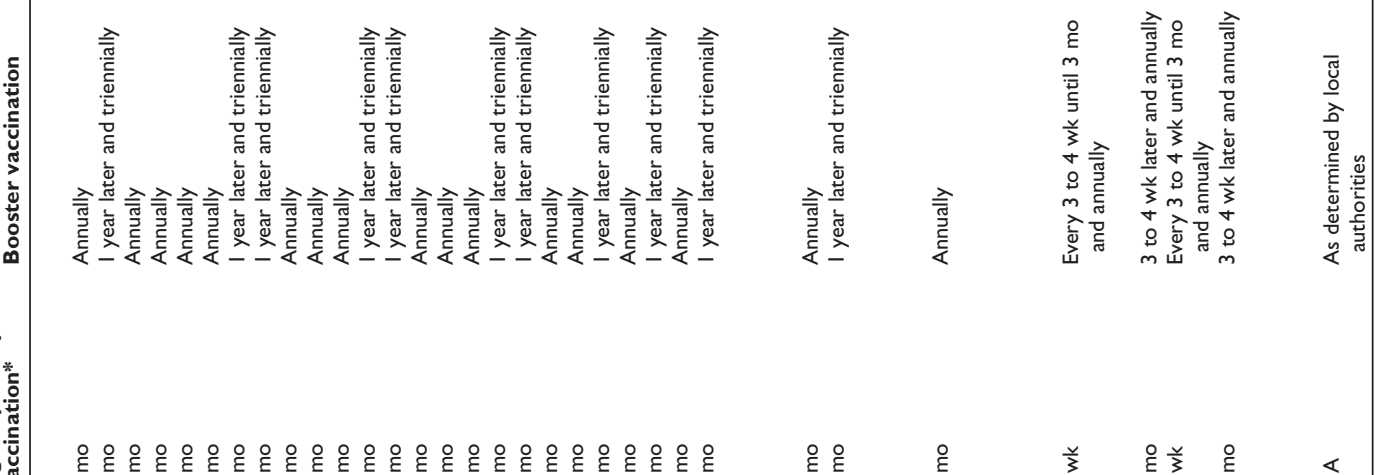

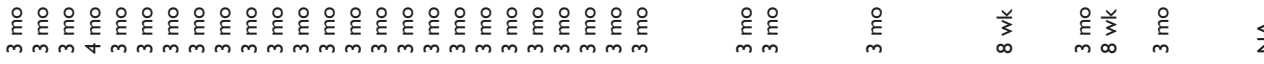

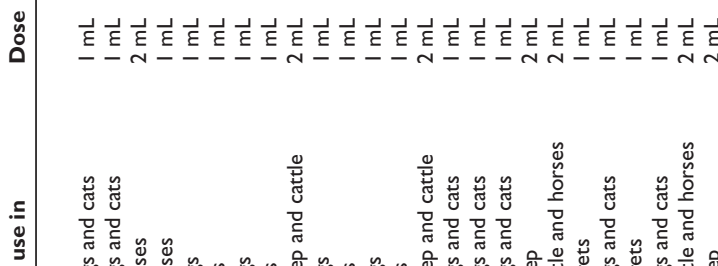

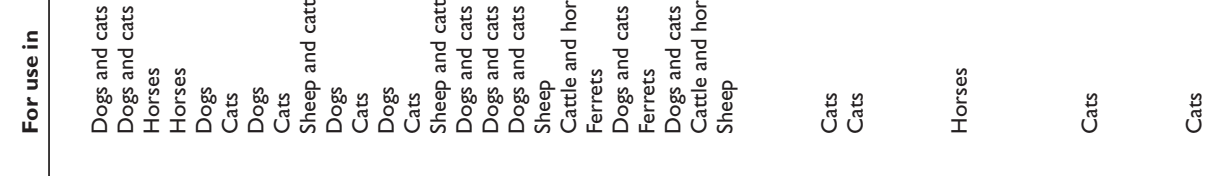

$$
\underline{\underline{\underline{U}}}
$$

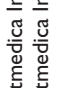

章

章$$
\Sigma \Sigma
$$

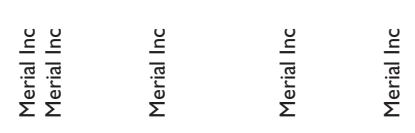




\section{Appendix 2}

Rabies vaccine manufacturer contact information

Manufacturer

Boehringer Ingelheim Vetmedica Inc

Merck Animal Health Inc

Merial Inc

Zoetis
Phone No.

800-638-2226 $800-52 \mid-5767$ $888-637-4251$ 800-366-5288
URL

www.bi-vetmedica.com www.merck-animal-health-usa.com us.merial.com

www.zoetis.com 